\title{
Odivelidades: binarismo cultural na construção identitária em cidade local amazônica
}

\section{Odivelidades: cultural binarism in the identity building to local city of Amazon}

José Guilherme dos Santos Fernandes - Doutor em Letras pela Universidade Federal da Paraíba (UFPB). Professor Associado e Pesquisador da Universidade Federal do Pará (UFPA). E-mail:mojuim@uol.com.br

Rondinell Aquino Palha-Mestrando em Estudos Antrópicos na Amazônia pela Universidade Federal do Pará (UFPA). E-mail: rondipalha@gmail.com

\section{Resumo}

Este estudo tem por finalidade caracterizar o binarismo cultural como composição de identidade em cidade local da Amazônia costeira, entendendo-se o conceito como a duplicidade e tensão entre atores sociais e suas práticas, no estabelecimento da hegemonia cultural. O recorte de pesquisa foram os fazedores e ativistas culturais de São Caetano de Odivelas (PA), que registraram suas impressões sobre os símbolos, agentes e territorialidades. O tipo de estudo foi retrospectivo, com construção de historiografia local, e prospectivo, com a aplicação de questionário com perguntas diretas. Foram utilizados os conceitos de centrípeto e centrífugo, centro e beira, enculturação e difusão, hegemonia, a fim de se discriminar os grupos e caracterizar as relações. O resultado considerou que as dicotomias são aparentes, posto que o espaço de negociação é uma constante na imposição das identidades, sendo frequente o binarismo intergeracional e intergrupal.

\section{Palavras-chave}

Binarismo cultural. Hegemonia. Cidade local. Identidade. Amazônia.

\section{Abstract}

This study aims to characterize cultural binarism as a composition of identity in a local city on the coast of the Amazon, understanding the concept as the duplicity and tension between social actors and their practices, in the establishment of cultural hegemony. The focus of research was cultural producers and cultural activists of São Caetano de Odivelas (PA), who registered their impressions about the symbols, agents and territorialities. The type of study was retrospective, with construction of local historiography, and prospective, with the application of a questionnaire with direct questions. The concepts of centripetal and centrifugal, center and border, enculturation and diffusion, hegemony were used in order to discriminate groups and characterize relationships. The result considered that the dichotomies are apparent, since the space for negotiation is a constant in the imposition of identities, with intergenerational and intergroup binarism being frequent.

\section{Keywords}

Cultural binarism. Hegemony. Local city. Identity. Amazon. 


\section{INTRODUÇÃO}

As cidades locais são caracterizadas pelo vínculo com os grandes centros urbanos regionais, sendo dependentes destes, seja pelo abastecimento ou pelos serviços, seja pela emigração de sua força produtiva aos grandes centros regionais, força esta que, posteriormente, envia recursos financeiros às suas famílias, que permaneceram nas cidades de origem. Para Santos (2008, p. 87, grifo do autor) o que caracteriza uma cidade local é "uma atividade polarizante e, dadas as funções que elas exercem em primeiro nível, poderíamos quase falar de cidades de subsistência". No caso das cidades da microrregião do Salgado paraense esta característica de localismo de cidade de subsistência, sem maiores especializações da produção, alia-se ao relativo isolamento que as cidades mais distantes do eixo da Estrada de Ferro Belém-Bragança (início do século XX) experimentaram quando do primeiro boom colonizador modernizante da região. Isto porque, por mais que a primeira e única ferrovia de integração do nordeste paraense tenha alcançado a cidade de Castanhal, esta cidade de referência do nordeste paraense, em 1885 (CRUZ, 1955), grande parte dos atuais municípios do Salgado permaneceram com difícil acesso por via terrestre, sendo o deslocamento até eles realizado em longas e perigosas viagens marítimas costeiras, até início dos anos 1960.

É o caso de São Caetano de Odivelas, considerada cidade de pequeno porte ${ }^{1}$, localizada na mesorregião do Nordeste do estado do Pará, microrregião do Salgado, mais precisamente em sua porção noroeste, no que poderemos designar como "esquina" da região, tendo ao norte o oceano Atlântico e a oeste a baía do Marajó. Historicamente, a cidade esteve isolada de comunicação e transporte mais imediato com outras cidades circunvizinhas, mesmo com a capital do estado, a cidade de Belém, que dista, por via terrestre, $110 \mathrm{~km}$ da sede odivelense. Para Fernandes (2007, p. 54):

as transformações urbanas mais substanciais ocorreram a partir dos últimos 50 anos, com o advento da estrada de rodagem e a consequente imigração para a cidade. (...) A maior dificuldade para a construção de uma

\footnotetext{
Segundo estimativa do IBGE (2019), a população do município é de 18.050 habitantes. A economia é baseada em pesca de diversas espécies e na coleta de crustáceos variados, em especial o caranguejo, que confere um simbolismo no estado como "o melhor" caranguejo do Pará. Esta atividade é mais intensa na região da foz do rio Mojuim, principal curso d'água do município, que se projeta para o oceano, no sentido sul-norte. Nas cabeceiras deste rio, região conhecida como Alto Mojuim, é mais intensa a agricultura, de teor familiar. A origem da cidade remonta ao século XVIII, como fazenda de produção de víveres para a missão jesuíta instalada na vizinha cidade da Vigia, esta criada enquanto vila no ano de 1693 (BAENA, 2014). Mas ao que tudo indica, em estudos recentes de Lopes, Fernandes e Silva (2020), a área em que está assentada a cidade é de antropização bem mais antiga, dada a recente descoberta de vestígios arqueológicos pré-colombianos no sítio Cachoeira.
} 
ligação mais direta com a capital, visto os mais de dois séculos e meio de existência, sempre foi a extensa área de manguezal, que confina a cidade em uma verdadeira "ilha", uma vez que o mangal forma um cinturão no seu entorno, que se estende por uma faixa de 4 a $5 \mathrm{~km}$ de largura: como vencer essa extensão até alcançar a terra firme? A saída mais óbvia, por longo tempo, até a construção da estrada, foi descer o Mojuim², ganhar o oceano, contornar a Ponta Itaipú e navegar no sentido sul até chegar à capital Belém.

Mesmo com provável origem em 1757 (BAENA, 2014), então chamada de Lugar Odivelas, a cidade sai de seu ensimesmamento somente após o advento da rodovia, iniciada nos anos 1950. Esta reclusão estabeleceu uma cultura mais endógena, entre "o isolamento comunitário e a dedicação ao trabalho com o mar" (FERNANDES, 2007, p. 55); diríamos mesmo que essa condição direcionou as práticas e valores locais para uma formação binária da sociedade, em vários aspectos do cotidiano das pessoas. É o que podemos classificar como binarismo social e cultural da cidade, isto é, a co-participação de aparentes elementos antagônicos, mas que se configuram como complementações necessárias de contrários epicizantes, dado o teor de atores contrários nesse aparente antagonismo: os clubes de futebol Marítimo/Progresso; os bois de máscaras Tinga/Faceiro; as bandas musicais Milícia/Rodrigues dos Santos; as localidades São Caetano/ Cachoeira; os bairros do Pepéua/Marabazinho; as regiões geográficas Foz do Rio Mojuim/Alto Rio Mojuim; os ecossistemas manguezal/terra firme; a atividade econômica pesca/agricultura.

Vale ressaltar que esse fenômeno do binarismo já era apontado por José Veríssimo, quando se referiu, em fins do século XIX, às cidades do interior do Brasil e da Amazônia:

Há, porém, em todas elas, ainda na mais humilde aldeia dos sertões do Pará ou de Pernambuco, da Bahia ou de São Paulo, do Paraná ou de Mato Grosso, dois partidos, dois chefes, alguns cabos eleitorais, os adeptos indispensáveis e, ao menos em vésperas de eleição, uma vida relativa. Não acharíeis ali algum gênero indispensável a vossa vida de perfeito civilizado, mas infalivelmente, matematicamente, encontraríeis o liberal e o conservador, inimigos políticos e particulares, decididos e irreconciliáveis (VERÍSSIMO, 1985, p. 63).

Essa dicotomia "civilizatória" na Amazônia também é marcada pela oposição centro-beira, que na visão de Velho marca uma nova orientação nas

\footnotetext{
Segundo os professores Ana Suelly Cabral e Aryon Rodrigues, do Laboratório de Línguas Indígenas da Universidade de Brasília, a palavra mojuim vem do tronco tupi-guarani, mais especificamente do tupinambá, provavelmente do século XVII, e significa "pequeno rio das cobras” (modzuí, mój, “cobra”, zý, “água”, í, sufixo diminutivo).
} 
frentes de expansão colonizadoras na região, justamente efeito das transformações nos modelos civilizatórios do século $\mathrm{XX}$, que arrastarão para a estrada os vínculos das cidades locais com os centros urbanos maiores. Se até fins do século XIX a beira do rio, e de outros cursos d'água, era um lugar melhor para viver, com lazer e poucas ambições capitalistas do homem comum, depois o centro da mata se torna o lugar da ambição e domínio da natureza a ser explorada, com o significado de trabalho árduo e enriquecimento. Com o advento das estradas na região amazônica os maiores aglomerados se localizarão cada vez mais distantes dos rios e com isso a nova beira passa a ser a beira da estrada (VELHO, 1981). Para o autor, "é de se notar como a frente agrícola e o seu avanço sempre estiveram associados à abertura de estradas e caminhos afastados da beira, buscando penetração e integração com as vias principais de comunicação e transporte" (VELHO, 1981, p. 148). Com isso, as cidades ribeirinhas do Salgado mudam seu perfil ao se tornarem cada vez mais dependentes dos polos urbanos, com ligação via terrestre. Ou quando não havia essa ligação, mantiveram-se por algum tempo como cidades locais e isoladas, como foi o caso de Odivelas.

Daí surge nosso problema principal: o binarismo cultural em São Caetano de Odivelas é resultante de processo histórico e social que impôs a dicotomia como instrumento de poder de grupos locais interessados na hegemonia de suas identidades? Em quais aspectos existe a negociação entre estes grupos locais para a manutenção do controle sobre as manifestações culturais? A hipótese é que existem práticas de cultura que garantem a vinculação e a interação destes aparentes opostos do binarismo social e cultural, tais como o parentesco, o compadrio e a manifestação cultural, notadamente os bois de máscaras, que aglomeram e mestiçam os grupos em princípio opositores: de fato são opostos complementares ou opostos co-dependentes. Em nosso entendimento, esta é a característica histórica que enformou e enforma o que poderemos classificar como identidade odivelense, ou odivelidade. Como decorrente desta hipótese, nossos objetivos neste artigo são: 1) discriminar os grupos em relação de codependência; e 2) caracterizar o binarismo nos eventos artísticos e culturais como constituintes da hegemonia cultural.

Mesmo não sendo novidade a questão da identidade em grupos em contato, em nossa abordagem queremos apresentar o sentido de odivelidade como a necessidade de se afirmar o caráter qualitativo da cultura odivelense, no sentido de sociabilidade de opostos pelo evento cultural. Em abordagem linguísticoetimológica, inicialmente entende-se este conceito como espaço de luta entre os grupos locais, posto que a partir do substantivo "odivelense", usual como gentílico entre os nativos, ao agregar-se o acusativo “-dade, -itãtis", formador 
de substantivos abstratos derivativos de adjetivação, tem-se a formação de palavra qualitativa, qual seja odivelidade, como a característica marcante do "ser" odivelense. Daí preferir-se este ao termo "odivelismo", que em sua formação traz a marca do verbo, gr. -ismós, formador de nome de ação. Ou seja, odivelismo tem mais a ver com um movimento (de pessoas, de grupo interessado em ser uma vanguarda) do que com a qualidade de ser algo (característica de ser e fazer), como o caráter qualificador do odivelense, nativo que assume sua pertença ao território. Portanto, optamos por odivelidade para tratarmos de marca identitária e sentimento de pertença do povo odivelense às suas tradições, práticas e valores.

Mapa 1 - Mapa com localização geográfica de São Caetano de Odivelas

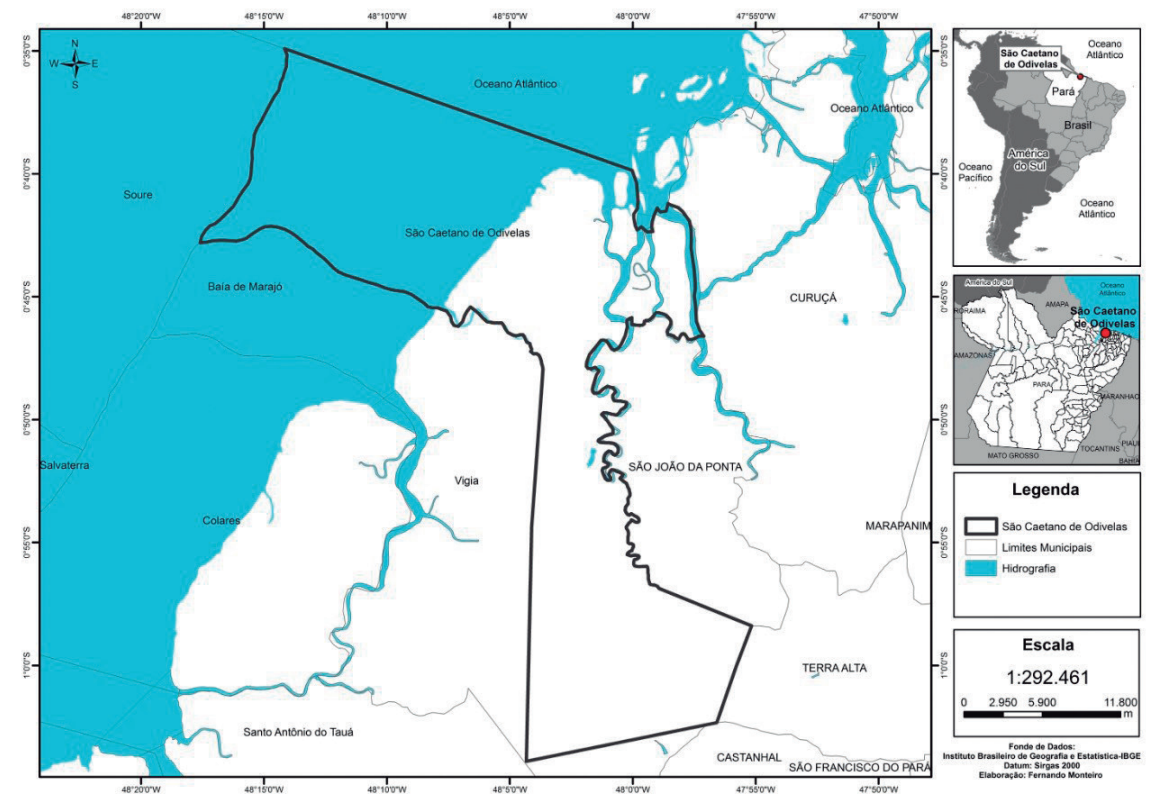

A maioria dos estudos realizados acerca de Odivelas nos últimos 20 anos, notadamente a partir do século XXI, dedicaram-se a tratar as manifestações culturais em si mesmas, em geral descoladas das condições históricas e sociais de produção, descrevendo-as e situando-as como eventos e produtos, pouco tratando dos produtores que assumem seus discursos e vozes como pensadores locais em conflitos e tensões sociais. Esses estudos acabam por afastar a produção cultural e artística dos processos sociais. Muitas seguem a retórica de Loureiro, que afirma certo impressionismo para discriminar a cultura amazônica, na linha bachelardiana da imaginação da matéria; vejamos em suas palavras: 
O caboclo, como homem amazônico, o nativo da terra, além de ter criado e desenvolvido processos altamente criativos e eficazes de relação com essa natureza, construiu um processo dissonante dos cânones dominantes. O caboclo humanizou e colocou a natureza à sua medida. Pelo imaginário, pela estetização, pelo povoamento mitológico, pelo universo dos signos, pela intervenção na visualidade, pela atividade artística, ele definiu sua grandeza diante desse conjunto grandioso que é o "mundo amazônico" (LOUREIRO, 1995, p. 34).

Ademais de uma verborragia imagística, o que observamos é uma generalidade quanto à figura de quem vive e labuta na região, na construção de uma categoria abstrata - o caboclo amazônico - que aparentemente só vive um devaneio sem ater-se aos conflitos sociais, produzindo-se uma representação evanescente, pouco afeita às condições de produção. Nesse sentido existe a dissertação de mestrado Boi Tinga: um cortejo de caricaturas em São Caetano de Odivelas (SILVA, 2004) e a tese de doutorado O boi e a máscara: imaginário, contemporaneidade e espetacularidade nas brincadeiras de boi de São Caetano de Odivelas - Pará (SILVA, 2011), ambas de Silvia Sueli dos Santos Silva. Além destes estudos, temos ainda os artigos: Tradição e contemporaneidade: o corpo e os processos de aprendizagem na dança do Boi de São Caetano de Odivelas (SILVA, 2009); É dia de folia: o folguedo do boi de máscara em São Caetano de Odivelas/PA (ALMEIDA; SANTOS, 2012); Boi de máscaras Faceiro: reflexões e contribuições metodológicas para o ensino musical infantil em São Caetano de Odivelas - Pa (CARDOSO, 2019); Composição Musical no Boi Tinga em São Caetano de Odivelas-Pa: história e Análises musicais musicais a partir do trompete Bb (MARQUES; MONTEIRO JUNIOR, 2020). Os estudos que mais se distanciam da perspectiva essencialista da arte e se ancoram nas condições sociais e históricas de produção são a tese de doutorado $O$ boi de máscaras: festa, trabalho e memória na cultura popular do boi Tinga de São Caetano de Odivelas, Pará (FERNANDES, 2004) e a dissertação de mestrado Entre a cultura popular e a arte urbana: a cidade de São Caetano de Odivelas - Pará nos murais contemporâneos de And Santtos e Adriano DK (COSME, 2020).

Em nosso entendimento, estudar a produção das manifestações artísticas e culturais deve considerar aspectos de uma sociologia da cultura no que se refere às instituições e às formas e efeitos destas produções (WILLIAMS, 2000), visto que as práticas sociais nas relações culturais produzem mais que continuidades, mas principalmente é um campo para tensões, conflitos, resoluções e inovações reais. Dessa feita, enquanto instituição social (organismo da sociedade com seus valores, práticas e interesses), pode-se dizer que a construção cultural em cidades locais da Amazônia assemelha-se ao que Gramsci tratou no ensaio "Alguns temas 
da questão meridional" (GRAMSCI, [1926] 2021). Isto porque à semelhança do Mezzogiorno italiano existem em cidades locais da Amazônia, para lembrar Veríssimo, duas classes em negociações e embates - conservadores e liberais que correspondem aos grandes proprietários rurais e grandes intelectuais, de um lado, e aos intelectuais da pequena e média burguesia rural, estes no mundo italiano de Gramsci. Em comparação mais grosseira, estas classes correspondem ao que vamos intitular, em nossa realidade amazônica, de políticos profissionais, aos primeiros, e de ativistas culturais, aos segundos. E no meio deles a grande massa, que são os odivelenses em busca de uma representação identitária, que faz o movimento pendular endógeno ou exógeno do binarismo cultural, quando buscam sua (s) identidade (s), nos eventos culturais.

Como um dos universais da cultura (BALÉE, 2012), a arte e as manifestações culturais são poderosas formas de socialidade, em razão de serem campos de disputas simbólicas pela hegemonia cultural, promotora da identidade que passa a ser atribuída como "nacional" por um grupo de poder. Para lembrar Gramsci, a hegemonia é a suplantação de uma classe sobre as demais mediante a persuasão e o consenso, e também pela força de repressão dos rituais da desordem. Enquanto persuasão e consenso, a relação entre grupos sociais em contato e disputa ocorre pelas negociações e permissividades nas manifestações, ora permitidas, ora controladas. É o caso histórico dos bois de máscaras de Odivelas, quando nos anos 1990 eram controlados seus cortejos para saírem somente após a missa na matriz do município. Esse controle aparenta ser um espaço neutro, mas reforça a "patronagem" dos santos e deuses, em um carnaval devoto hierarquicamente ordenado (DA MATTA, 1986). A aparente interação harmoniosa entre os indivíduos pertencentes ao mesmo grupo social, garante $O$ que poderemos classificar como coletividade, ou melhor, sociedade em sentido mais originário: “o significado primário de sociedade era companheirismo ou camaradagem" (WILLIAMS, 2007, p. 379), mas oculta os recortes e cisões internas, particularmente em cidades locais.

Entendida como compósito de opostos e binarismos, a identidade tem a ver intrinsecamente com o conceito de sociedade, ou sociabilidade, como faculdade que estrutura os grupos sociais em companheirismo, e enquanto "camaradagem", num sentido mais estrito, como o companheirismo de pequenos grupos, em contraponto às sociedades complexas modernas. Portanto, esse companheirismo ou camaradagem em cidades locais, pouco infensas à entrada 
de indivíduos alóctones ou contatos mais tensos com grupos alienígenas, maquia com um sentimento de pertencimento coletivo o que de fundo apresenta tensões. Por isso, não podemos professar que tenha havido, na realidade odivelense, uma identidade raiz, que unificasse quase que ditatorialmente os indivíduos da cidade, mesmo que tenha havido longo período histórico de relativo isolamento. Isto porque a compreensão de identidade que mais pode se adequar ao processo que estamos tratando aqui é de que:

as identidades não se constroem a partir de um conjunto estável e objetivamente definível de "traços culturais" - vinculações primordiais -, mas são produzidas e se modificam no quadro das relações, reações e interações sociossituacionais - situações, contexto, circunstancias -, de onde emergem os sentimentos de pertencimento, de "visões de mundo" identitárias ou étnicas (CANDAU, 2016, p. 27).

Apoiados em Da Matta (1986), podemos inferir que a pertença dos odivelenses tem se instituído mediante as festas da ordem e da desordem, segundo sejam promovidas por conservadores ou liberais, ou mesmo pelo misto dos dois segmentos, por isso a dicotomia não é radical, mas negocial em direcionamentos endógenos ou exógenos, como veremos mais adiante como característica do binarismo cultural. Porque:

se os ritos da desordem promovem temporárias des-construções ou rearrumações sociais, os ritos da ordem marcam de forma taxativa quem é o ator e quem é o espectador [...]. Daí, certamente, a associação entre cerimonial e poder. É que o ritual reveste o poder, dando-lhe uma forma exterior solene e legítima (DA MATTA, 1986, p. 86-87).

Por isso, podemos afirmar que, mesmo a despeito de ser uma sociedade aparentemente mais originária e portadora de tradição ancorada no relativo insulamento, mais cabe tratar a construção identitária da odivelidade como uma identidade mista entre a modernidade do estado-nação, daí ser composição de um sujeito sociológico, e a pós-modernidade do sujeito fragmentado, daí ser composição de um sujeito relacional, via de regra aquele que alçou outros espaços alóctones e retornou ao território de origem. Isto porque por mais que haja uma dicotomia é como se o binarismo social e cultural aventado implicasse na afirmação de um ou outro polo (afirmação de identidade raiz); mas sem a presença do outro, em sentido relacional e co-dependente, não haveria nenhum dos dois polos (identidade rizoma). O que é reiterado por Hall: 
A identidade surge não tanto da plenitude da identidade que está dentro de nós como indivíduos, mas de uma falta de inteireza que é "preenchida" a partir de nosso exterior, pelas formas através das quais nós imaginamos ser vistos pelos outros (HALL, 2000, p. 39).

Mas existe uma característica básica que determina o que é ser odivelense, com traços históricos, materialidades e caráter do indivíduo com sentimento de pertença? Poderemos tratar de uma sistemática que conforma esse caráter do "ser" odivelense, disposta em dois movimentos: os centrífugos, com a identificação dos saídos da terra para buscar melhora econômica e social em suas vidas, bem como o reconhecimento por serem os portadores das novidades do mundo exterior àquela sociedade (ex. dos nativos que ascenderam na carreira militar ou nos estudos superiores), e os centrípetos, com a constituição de identidade local por aqueles que permanecem na terra e criaram estratégias de sobrevivência para os que ficam (os políticos e os ativistas culturais locais). Interessante observar que estes conceitos vem ao encontro do caráter de nacionalismo de estado, quando se pode identificar o nacionalismo centrífugo com uma unidade política autônoma do Estado, que almeja mais independência, enquanto que o nacionalismo centrípeto está mais arraigado no Estado soberano (ROMÃO, 2012): para nosso caso a analogia funciona pelo primeiro representar a dissolução aparente de quem parte e se distancia do vínculo telúrico, ao contrário do que é mais reforçado pelos demais que se deixam ficar na terra.

Essa sistemática de direcionamentos opostos não se constitui em um movimento ordenado no sentido de ser uma formação cultural instituída por artistas ou artesãos, mas antes um sistema de sinais (WILLIAMS, 2000) enquanto formas e características estéticas construídas pelas instituições e permeadas pelas relações sociais e de poder; até existe uma identificação grupal, mas esta é circunscrita a trabalhos eventuais, em conjunto, e a relações de sociabilidade mais amplas. Esta mirada de movimentos exógenos e endógenos vem a ser a contribuição deste estudo para a uma sociologia da cultura, especificamente em cidades locais, a exemplo de São Caetano de Odivelas. Estas podem ser consideradas, em muitos casos, como cidades ribeirinhas, a exemplo de Odivelas, às margens do rio Mojuim e próxima à foz deste, como observamos na imagem aérea disposta na Figura 1. 
Figura 1 - Imagem aérea de São Caetano de Odivelas, vendo-se em primeiro plano o rio Mojuim

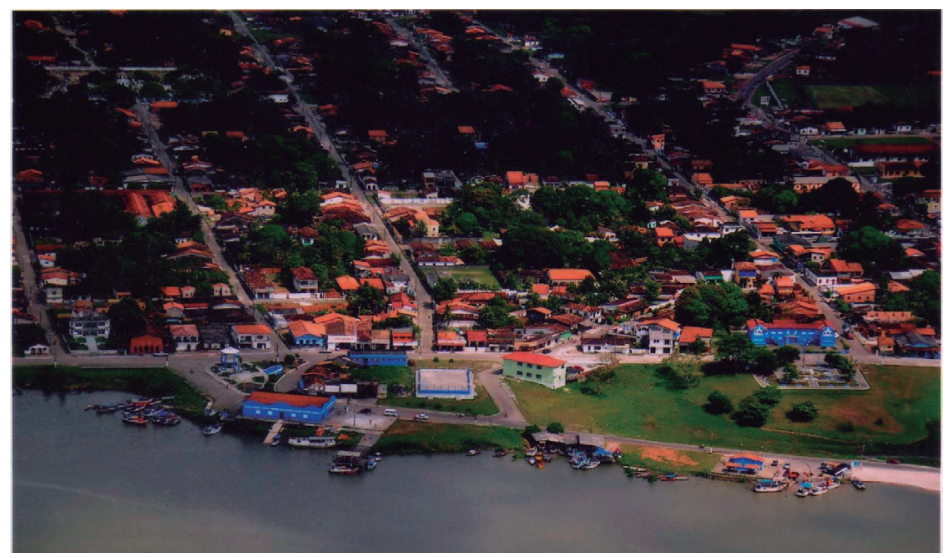

Fonte: Biblioteca Pública Municipal de São Caetano de Odivelas.

\section{MATERIAL E MÉTODOS}

Tratar de identidade em São Caetano de Odivelas remete a valores, produtos e práticas diretamente ligadas às manifestações como os bois de máscaras ${ }^{3}$, as bandas de música, as celebrações e procissões religiosas, bem como à sua culinária e hábitos cotidianos voltados ao rio, como a pesca e o extrativismo, principalmente do caranguejo. Estas práticas de cultura são transmitidas e transferidas intrinsecamente entre os indivíduos locais, através da (con) vivência intergeracional, afirmando-se a enculturação:

Learning how to live in the society of which one is a member is called enculturation. Diffusion is the adoption of cultural traits and behaviors by a recipient society from a donor society. thefore, enculturation and diffusion involve one action common to both: transmission of culture, enculturation is the transmission of culture across time, from one generation to the next (BALÉE, 2012, p. 54).

3 O boi de máscaras é uma manifestação própria dos odivelenses, datando sua origem dos anos 1930. Pode ser considerada uma variação do boi-bumbá comum às diversas regiões do Brasil, mas tem a particularidade de não ser uma dança dramática, isto é, não é uma encenação teatral, com enredo e personagens. Ele ocorre, em geral, nos meses carnavalesco e junino, mediante um cortejo em que participam músicos, brincantes (fantasiados de cabeçudos, buchudos e pierrôs) e a audiência pública (os mutucas) que acompanha o grupo pelas ruas de São Caetano de Odivelas. Sua dinâmica ocorre mediante movimentações e paradas nas ruas da cidade, diante de residências que previamente solicitam a apresentação, o que se chama de carteado. Existem dois ritmos marcantes nas exibições, o samba e a marcha, que são tocados por instrumentos de sopro e de percussão, enquanto os brincantes fazem hilariantes evoluções em torno da figura central da festa, o boi-bumbá ou boi de máscaras. São diversos os grupos de boi de máscara no município, mas dois particularmente são os mais antigos, o Boi Tinga e o Boi Faceiro. 
Vista como uma transmissão da cultura em sentido horizontal, a enculturação pressupõe também a difusão como transmissão horizontal, o que se estabelece nas tensões e negociações entre os "conservadores" políticos profissionais e os "liberais" ativistas culturais: para fins deste estudo são os nossos objetos de análise, em suas práticas e discursos. No primeiro caso, enquanto prática, trataremos dos eventos e atores que construíram o que se pode designar como cultura odivelense ou odivelidade, no tópico abaixo Historiogafia do espaço estudado. Quanto aos discursos, utilizaremos as falas e narrativas apresentadas pelos ativistas culturais, ou fazedores de cultura, e postas no questionário apresentado no tópico Falas e discursos dos fazedores de cultura. Para a interpretação destes discursos, tratados em Resultados e Discussão, utilizaremos a Análise do Discurso (AD) como procedimento metodológico deste corpus. Para tanto, serão aplicadas as categorias de dito e não-dito; posto e pressuposto; paráfrase e polissemia (ORLANDI, 2003), categorias estas que estarão em diálogo interdisciplinar com as de centrípeto e centrífugo; enculturação e difusão; centro e beira; e intelectuais e proprietários.

\subsection{HISTORIOGRAFIA DO ESPAÇO ESTUDADO}

Em perspectiva conservadora e tradicionalista, observamos em São Caetano de Odivelas a condução de movimentos socioculturais por parte de políticos, vereadores e prefeitos, que ocupavam o cargo com propósito de barganhas políticas e eleitoreiras, trazendo, com o devido tempo, prejuízos aos coletivos por eles conduzidos. Essa dicotomia política e social pode ser observada nos clubes de futebol, como Progresso Esporte Clube (originado em 1924) e Marítimo Esporte Clube Odivelense (originado em 1937), os dois mais tradicionais clubes esportivos de São Caetano de Odivelas, bem como nas centenárias bandas de música Rodrigues dos Santos (1881) e Milícia Odivelense (1904); ou nos movimentos religiosos, como o Movimentos de Casais Católicos Odivelenses (1984), e nas associações comunitárias, como Clube de Mães Odivelense (1979), Cooperativa Mista de Pescadores (?) e Sociedade Literária Odivelense (1978).

Originalmente, a direção de organizações sociais proporcionava uma aparente sensação de apoio dos políticos profissionais, mas com prazo de validade, pois, depois do fim de mandato ou gestão, essas organizações retornavam à sua real situação de dependência da ajuda externa da comunidade, 
que não os políticos eleitos que têm por base essas organizações sociais, o que mantinha a enculturação como prática reinante. Isso é um fato recorrente nas instituições civis de São Caetano de Odivelas. Diante desse quadro é possível encontrar, de outro lado, entidades e/ou coletivos direcionados por ativistas culturais (que consideraremos aqui "fazedores" de cultura local) que conflitam com o comportamento revanchista de gestores políticos, pouco preocupados com o desenvolvimento sociocultural da municipalidade.

Somente na década de 1990, quando houve a eleição e posse da presidência da banda de música Rodrigues dos Santos, a situação historicamente instituída começou a sofrer tênues alterações, quando a difusão cultural, enquanto adoção de traços exógenos, ganha destaque. O presidente eleito, o então sargento da Polícia Militar Paulo Roberto Melo, era oriundo do próprio corpo musical da instituição. Era um indivíduo representante dos centrífugos, daqueles que haviam deixado o Município para adquirir melhor formação acadêmica e retornar à cidade, sem perder sua identidade com a terra materna. Essa atitude foi o pontapé inicial para que outros coletivos sociais e culturais seguissem o mesmo caminho. Com a experiência dos retornados foi possível dinamizar propostas e objetivos, reorganizar atividades e fortalecer a identidade sociocultural dos munícipes, isso somado ao anseio de crescimento cultural dos que permaneceram, surgindo a necessidade de uma compreensão identitária própria através das manifestações, costumes e hábitos característicos dos odivelenses.

$\mathrm{Na}$ década de 1990, começaram a surgir grupos voltados para atividades culturais mais específicas, como o Grupo de Tradições Populares Sauatá, grupo criado a partir da influência das quadrilhas juninas ${ }^{4}$ Roceiros da Baltazar e Explosão do Cheiro, então com muita força dentro do cenário junino odivelense, e com a participação de integrantes dos movimentos de base da igreja católica, como o grupo de jovens. Em 1996, surgiu o Grupo Teatral Art da Terra, que foi criado a partir do fortalecimento da participação de jovens nas atividades da paróquia católica da cidade. Em consequência, houve a criação do "Auto da Paixão de Cristo", em 1997 e o Resgate do Boi Faceiro, em 1998, hoje atrações culturais marcantes no calendário da cidade.

\footnotetext{
As quadrilhas juninas Roceiros da Baltazar e Explosão Junina, a primeira fundada em 1984 e a segunda em 1991, fizeram parte da cena junina de São Caetano de Odivelas durante a década de 90. Eram consideradas duas das principais atrações artísticas do Município, dividindo com os bois de máscaras Tinga e Faceiro a popularidade junto aos moradores locais, principalmente entre a juventude. As duas encerraram suas atividades nos anos 2000, a Explosão Junina em 2004 e a Roceiros da Baltazar em 2009, em virtude do alto custo desta brincadeira junina e o desinteresse dos jovens em participar da atividade cultural.
} 
Os jovens integrantes e responsáveis pela retomada do Boi Faceiro estavam inseridos e comprometidos com as práticas e com o saber fazer cultural odivelense. A retomada do Boi Faceiro foi o (re) começo para que outros grupos de bois de máscaras retornassem à cena, ao mesmo tempo que incentivou o surgimento de novos grupos, possibilitando a participação direta de jovens na concepção da manifestação cultural dos bois de máscaras em todos os seus momentos.

Esse contexto fortaleceu a identificação da juventude odivelense com suas próprias tradições e costumes. Vale destacar que o revival cultural aconteceu entre os jovens, mas desde os anos 1930 o Boi Tinga, como o mais antigo boi de máscaras, mantinha-se em atividade, como uma manifestação localizada (capitaneada por uma única família da cidade) e sazonal (em junho), mas não com o alcance de marca identitária que passa a adquirir a manifestação de outros coletivos de boi de máscaras, o que começa a ocorrer, mais intensamente, em vários grupos de bois de máscaras em meados dos anos 1990.

Paralelo ao movimento, específico dos jovens atuantes no Art da Terra, houve o fortalecimento das escolas de música, especialmente da Banda Musical Rodrigues dos Santos, (re) construindo o formato de apresentação da banda tradicional de coretos, baseado antes apenas nas alvoradas musicais e tocatas nas procissões religiosas e eventos políticos. Surgem os concertos musicais mais elaborados e públicos, no estilo big band (com levada instrumental associada ao jazz), para os eventos e festivais culturais no município e na capital do Estado. Formato este, também, seguido pela Banda Milícia Odivelense.

Tais características provocaram incentivos aos alunos-músicos a buscarem novas perspectivas de futuro, mas sem perder a identidade com as raízes locais. Por exemplo, jovens que já integravam o corpo musical da banda, mas que, por motivos particulares, iam em busca de novas alternativas, retornavam para participar da banda em dois momentos, na comemoração de aniversário do grupo e para participar da procissão do círio do padroeiro da cidade.

O trabalho realizado nas escolas de música entusiasmou os jovens odivelenses a buscar capacitação, formação superior e especialização fora da cidade para depois desenvolverem trabalhos voltados para o fomento da musicalidade local, como destacado em investimentos das bandas de música em big band, o que originou festivais como o Odivelas Música (Figura 2). 
Figura 2 - Apresentação de big band durante o Odivelas Música (2010), com integrantes das bandas musicais "Milícia Odielense" e "Rodrigues dos Santos", em frente à Prefeitura da cidade

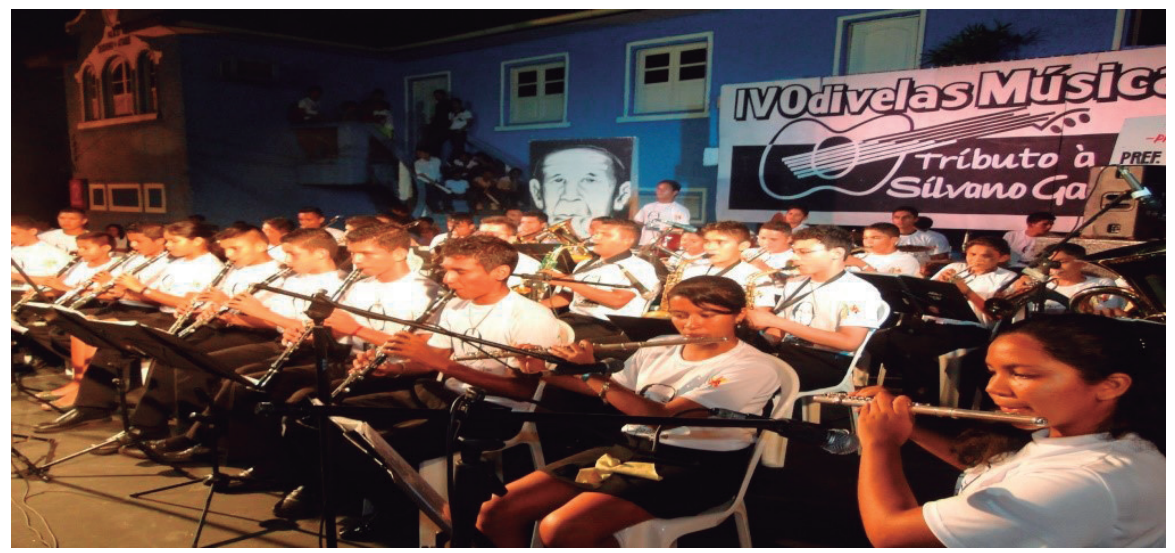

Fonte: Associação Mestre Bené.

O conceito de um certo "odivelencismo" ia de encontro à política institucional, antiquada e parcial da gestão pública local dos políticos profissionais, pois não se percebia políticas públicas que vislumbrassem a cultura como um elemento importante para o desenvolvimento social da comunidade odivelense, em acordo com o que preceitua, desde 1988, o Art. 215 da Constituição Federal: "O Estado garantirá a todos o pleno exercício dos direitos culturais e acesso às fontes da cultura nacional, e apoiará e incentivará a valorização e a difusão das manifestações culturais" (BRASIL, 2006, não paginado). Cônscios dos direitos culturais, a juventude passa a se empenhar na realização de manifestações de agregação e fortalecimento das culturas locais, inclusive de origem religiosa, como a Paixão de Cristo (Figura 3).

O movimento dos jovens, principalmente, ganhou força e adeptos, sendo criadas possibilidades de vazão da odivelidade através do Odivelas Música ${ }^{5}$, da inserção do boi de máscaras no carnaval $^{6}$ e do fortalecimento de atividades

Odivelas Música é um festival de música promovido pelas bandas Rodrigues dos Santos, Milícia Odivelense e Associação Mestre Bené. O evento foi pensado e idealizado por Márcio Cardoso, Nildo Zeferino, Rondi Palha e Afonso Santa Rosa, tendo sua primeira edição em 2005, com o objetivo de promover e valorizar a produção musical odivelense, com a participação de músicos e artistas locais. O ponto alto do evento foi o festival de música cover e o concerto da banda Odivelas Música. A cada ano um mestre de cultura popular local era homenageado no evento, durante a realização do festival, que no momento está suspenso por falta de apoio do poder público.

6 Em 2006, o boi de máscaras passou a compor a programação do carnaval de São Caetano de Odivelas como forma de promover a singularidade do carnaval odivelense em contraponto à homogeneidade que estava ocorrendo nos carnavais do interior do Pará, em particular o apelo 
culturais já instituídas (como o Auto da Paixão de Cristo). Além disso, houve uma provocação para a realização de atividades de transmissão de conhecimentos artísticos, como cursos e oficinas de pinturas em mural, confecção de boi e confecção de miniaturas e máscaras de pierrôs, em parcerias entre a Associação Mestre Bené, (antigo Grupo Art da Terra) e a Secretaria Municipal de Cultura e a Fundação Curro Velho (governo do Estado do Pará), como meio de fomentar a identidade cultural local. Estas oficinas foram ministradas por mestres e artesãos locais, dentre os quais Mestre Dorrêis, Ricardo Santos (Dãe), Eudis Aquino e Anderson Santos (And Santtos). Até o início dos anos 2000, oficinas com estas características eram algo relativamente raro no contexto municipal.

Figura 3 - panorâmica da apresentação da Paixão de Cristo, realizada pelo grupo de teatro 'Art da Terra", no ano de 2017

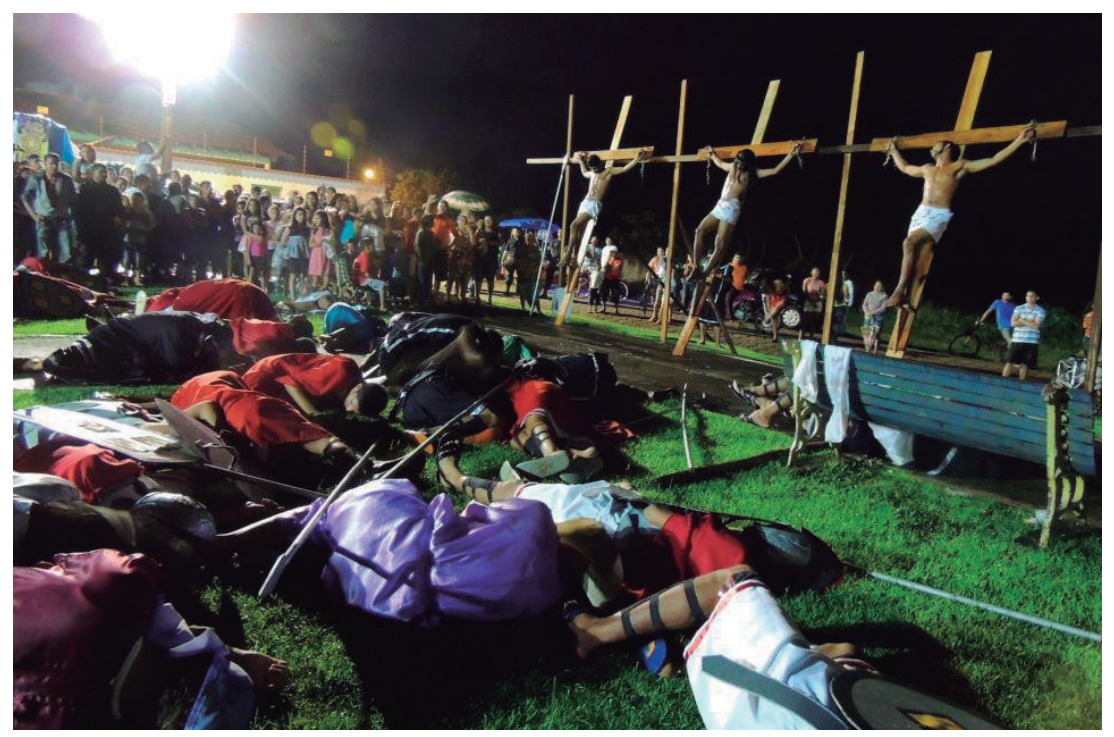

Fonte: Associação Mestre Bené.

Durante essa animação coletiva dos fazedores de cultura, alguns artistas, músicos e grupos culturais ganharam destaque no cenário regional e nacional. Os artistas odivelenses foram destaques na Revista Ver-o-Pará, em edição especial do ano de 1999, ganhando notoriedade, na referida publicação, Antonio Cação, então em primeiros passos na confecção de máscaras de pierrôs dos bois de máscaras; Mestre Preiá (in memorian), artista que se destacou na confecção de cavalinhos, máscaras e esculturas em troncos de madeira; além de Mestre Dorrêis

ao estilo "baiano" de se realizar a festa. A iniciativa foi do Boi Faceiro, sendo precursor na proposta de arrastões de bois de máscaras no carnaval. Em 2009, o Boi Tinga, passou a realizar também o arrastão no carnaval. 
(in memorian), considerado até hoje referência nas artes plásticas da cultura dos bois de máscaras. Em 2004, durante o Salão Arte Pará, promovido pelas Organizações Rômulo Maiorana, em Belém do Pará, alguns artistas odivelenses participaram da mostra livre, a exemplo de Mestre Preiá, Lúcio Chagas, Edgar de Santana Garça e Edgar Junior.

No ano de 2019, tivemos a participação dos artistas visuais And Santtos, na VII Bienal dos Países Lusófonos e na I ExpoAmazônia em Portugal, e Adriano DK, em exposições independentes na Itália. Também, destacamos a participação do boi de máscaras Tinga, no III Festival Internacional de Máscaras Ibéricas, em Lisboa (Portugal), e do Boi Faceiro, no Fórum Social Mundial de Belém, em 2009, bem como no I Colóquio Internacional de Etnocenologia, em Belém do Pará, no ano de 2018. Temos ainda a participação da Banda Rodrigues dos Santos no Festival Internacional de Música das Américas, nos anos de 2017, 2018 e 2019, realizado em Belém do Pará. Estes são alguns exemplos da participação de grupos e artistas que marcam sua produção como expressão da identidade odivelense.

\subsection{FALAS E DISCURSOS DOS FAZEDORES DE CULTURA}

Para além da historiografia dos movimentos culturais invisibilizados na cultura local, desenhada a partir de diálogos informais com os ativistas culturais da cidade (pesquisa retrospectiva), buscou-se um instrumento mais formal para a produção de dados, mediante a pesquisa prospectiva, com aplicação de questionário com perguntas diretas, em estudo observacional e aplicado, o que caracterizou nossa pesquisa como marcantemente transversal, posto que registramos nossas informações sem alterar ou manipular o ambiente. $O$ fator de inclusão foi a escolha de fazedores/ativistas culturais presentes no evento Multicampiartes - Caravana Cultural, promovido pela Pró-Reitoria de Extensão da Universidade Federal do Pará (UFPA), em parceria com o Núcleo Universitário de São Caetano de Odivelas (NUSC) da referida Universidade. O evento, ocorrido de 16 a 20/09/2019, teve por finalidade promover iniciativas culturais e artísticas na cidade, unindo o saber produzido na UFPA aos saberes e ao desenvolvimento das comunidades, de forma que os dois saberes sejam fortalecidos.

Por meio da realização de diversas atividades artísticas e culturais, que valorizaram o aperfeiçoamento teórico e prático, o evento socializou, experimentou e divulgou as artes e manifestações culturais locais. Uma dessas atividades foi o Seminário Conexão Cultural, atividade em que houve a interação dos grupos e diversos fazedores culturais locais com os acadêmicos, a fim de tratarem das demandas e possíveis direcionamentos acerca da implementação de ações 
transformadoras para as manifestações da cidade. Nesta oportunidade, buscou-se "ouvir" a narrativa desses fazedores de cultura local, notadamente as lideranças das manifestações culturais locais, desde que aceitassem responder ao questionário. Não é demais afirmar que o destaque para a narrativa de indivíduos, enquanto instrumento da memória, é ancorada no que diz Fernandes (2011, p. 39):

A memória é a faculdade de reter as ideias, impressões e conhecimentos adquiridos anteriormente ao momento presente da rememoração, considerando-se a experiência individual, mesmo que ocorra a partir de um fato acentuadamente coletivo. No entanto, a memória só tem razão de ser por seu caráter de transmissão, ou seja, ela se constitui individualmente, a partir das experiências do sujeito retidas em suas funções psíquicas, mas adquire uma dimensão social por se tratar de ato interativo da cultura: eu narro sempre a outrem e, particularmente, em sua modalidade oral a transmissão requer obrigatoriamente um interlocutor. Por isso a memória assume um caráter de tradição, aprendizagem e poder.

Solicitou-se, a partir da visão dos presentes, o que mais representava, em práticas cotidianas e festivas, a odivelidade, nas ocasiões em que pessoas de fora de São Caetano de Odivelas se referiam aos odivelenses ou à cidade. Por fim, questionou-se se os odivelenses retornados (movimento centrífugo) têm sentimento de identificação com o território, vindo à cidade com frequência por se sentirem mais acolhidos.

Participaram do Seminário cerca de 40 fazedores de cultura, mas somente nove (9) participantes responderam às seis questões formuladas. Deste montante de respondentes, cinco (5) foram homens e quatro (4) foram mulheres, com idades entre 20 e 60 anos, em sua quase totalidade artesãos envolvidos na confecção de máscaras e vestimentas dos bois de máscaras e músicos que tocam nas bandas locais e nos cortejos dos referidos bumbás, além de líderes comunitários e ativistas ambientais e de gênero, por vezes com duplicidade de atuação social. Não identificamos os participantes do questionário, nos referimos a eles mediante letras, de A ao I, como maneira de preservá-los em razão de alguma eventual incompreensão de suas respostas por parte de grupos políticos antagônicos, na cidade. Foi entregue questionário impresso com as perguntas, e as respostas foram por escrito, em conformidade com a opinião de cada um(a) entrevistado (a), após apresentação de reflexão sobre cultura e identidade, por parte do condutor da atividade, aluno de pós-graduação do PPG em Estudos Antrópicos da Amazônia, do Campus de Castanhal, da Universidade Federal do Pará (UFPA).

O perfil dos entrevistados é bem diversificado quanto ao recorte etário, ao grau de instrução e à atuação profissional, tendo em comum que todos (as) são atuantes no movimento cultural local (ver Quadro 1). 
Quadro 1 - Perfil dos entrevistados

\begin{tabular}{|c|c|c|}
\hline \multirow{2}{*}{ VARIÁVEIS } & \multicolumn{2}{|c|}{ DADOS } \\
\cline { 2 - 3 } Grau de Instrução & CARACTERÍSTICA & QUANTITATIVO \\
\hline \multirow{3}{*}{ Idade } & Superior & 3 \\
& Médio & 5 \\
& Fundamental & 1 \\
\hline \multirow{4}{*}{ Atuação Profissional } & $<30$ anos & 3 \\
& $31-49$ anos & 4 \\
& $>50$ anos & 2 \\
\hline & Professor & 3 \\
& Estudante & 1 \\
& Artesão & 1 \\
& Aposentado & 1 \\
& Pescador & 1 \\
& Músico & 1 \\
\hline
\end{tabular}

Fonte: Elaboração dos autores.

A diversidade dos participantes resultou em ampla variação nas respostas nos questionários, tratadas a seguir.

\section{RESULTADOS E DISCUSSÃO}

Relativo à primeira pergunta - a) Existe uma característica que determina o que é ser odivelense? -, observamos que, recorrentemente, a característica está vinculada ao ambiente natural - $O$ meio ambiente natural como os manguezais, as matas de várzea, os bairros da cidade e seus costumes, amar São Caetano de corpo e alma (Entrevistado A) - ou ao envolvimento com as manifestações culturais próprias da cidade - Sim, a cultura popular, os bois, as procissões, as bandas os festivais, a comida. A cultura odivelense é muito rica (Entrevistado E); Participar nos bois de máscaras, pois desde crianças todos participam dessa brincadeira (Entrevistado F); Sim a participação nos bois e no festival do caranguejo. Não tem nada mais odivelense que isso! (Entrevistado B). Isto quando não houve uma mistura destes aspectos: $O$ odivelense nato tem que se relacionar com o rio Mojuim, com os bois de máscaras e com as bandas de música (Entrevistado I); Acredito que as alvoradas das bandas de música e os eventos culturais tem um charme próprio que só tem na cidade (Entrevistado C). 
No tocante à segunda pergunta - b) há uma, ou mais, tradição oral e coletiva que esteja vinculada tão-somente ao território odivelense? -, obteve-se em primazia a referência a outro produto da cultura local, a culinária - $A$ culinária de São Caetano de Odivelas só pode ser produzida aqui (Entrevistado D) - mas sem descuidar-se de outros elementos repetidos na questão anterior, que são os bois, as bandas e o festival do caranguejo, e também a presença de um elemento compósito nas culturas populares, a religiosidade em seu aspecto mais profano, de círios e procissões - Sim, as bandas centenárias, os bois de máscaras e a religiosidade do povo. (Entrevistado G); A culinária típica, a tradição dos bois nas ruas, o festival do caranguejo, o dia a dia dos moradores são próprios da Cidade (I).

Com isso, a terceira pergunta $-\mathrm{c}$ ) as práticas de cultura que ocorrem no território odivelense só podem ser realizadas unicamente neste espaço? apresentou respostas que acentuam a autenticidade do espaço odivelense como único em que se pode realizar as referidas manifestações culturais - Algumas práticas sim, só podem ser realizadas no ambiente odivelense como a brincadeira do boi, o festival do caranguejo e algumas celebrações (Entrevistado C) - mesmo que os fazedores de cultura locais possam se deslocar para auferir o reconhecimento da identidade odivelense em outros espaços: As celebrações religiosas, os eventos culturais só podem ocorre em nosso território. Os grupos culturais podem se apresentar em diversos outros lugares (Entrevistado E). É como se subliminarmente houvesse uma estratégia para que a cultura odivelense fosse marcada pelos alóctones a partir da inserção em outros territórios, para a identificação: As nossas traições precisam se mais expandida para outras cidades e em outros estados (Entrevistado A); Nossos grupos e nossas bandas devem ser levadas para outros lugares para valorizar mais nossa cultura (Entrevistado $\mathrm{H}$ ).

O que fica afirmado mais ainda com a quarta questão - d) as pessoas de "fora" conseguem observar em nossas práticas cotidianas e festivas algo que nos diferencie delas? -, nas seguintes respostas: As pessoas de fora admiram principalmente as bandas de música e os bois de máscaras, Tinga e Faceiro (Entrevistado B); Sim, as pessoas que vêm de fora gostam do carnaval por ser diferente por causa dos arrastões dos bois (Entrevistado C); Sim, há uma admiração no nosso prato típico que é o caranguejo (Entrevistado H); Há uma impressão boa que se refere a hospitalidade dos odivelenses, bem como a suas tradições culturais e culinárias (Entrevistado I). É de destacar, novamente, os bois de máscaras, o caranguejo e as bandas de música como tradições vinculadas ao território odivelense, acrescidas da religiosidade. 
A quinta pergunta - e) existem valores e práticas mais universais que no território odivelense adquirem uma característica peculiar/ própria? - marca a relação entre o local e o universal, instigando-se os entrevistados a opinarem sobre a criatividade local em relação àquilo que é importado para sua cultura: Sim, o carnaval acontece em todos os lugares, mas, em São Caetano, tem os bois e as bandas de música (Entrevistado B); A pescaria acontece em muitos rios, mas em São Caetano o rio é mais especial. Também, tem bandas em outros lugares, mas só aqui tem a Milicia e a Rodrigues que tocam pelas ruas (Entrevistado C); A brincadeira do boi tem no Brasil inteiro e em São Caetano de Odivelas tem os nossos bois de máscaras que são únicos (Entrevistado D). Mais uma vez a presença dos bois como grande referência local, além de elementos que se aglutinam a estes, como bandas de música e o espaço fluvial do Mojuim. Há de se destacar, no entanto, a presença do binarismo, já aventado como base da cultura local, pois faz-se referência às bandas Milícia Odivelense e Rodrigues dos Santos, que são opostos complementares e codependentes, em atitude necessariamente relacional para a afirmação de ambas como representações da odivelidade, o que é subliminarmente reconhecido pelo entrevistado que automaticamente as cita como um único elemento de cultura.

Isto fica latente quando, na sexta pergunta $-\mathbf{f}$ ) os odivelenses que moram em outro espaço que não o território odivelense retornam com frequência a este por se sentirem mais acolhidos, confortados sentimentalmente? -, há clara referência ao retorno, mesmo que não definitivo, quando dos eventos culturais ou mesmo o sentimento de "saudosismo" pelo lugar de origem: Sim. Porque nunca perdem suas raizes e sempre que é possivel retornam para matar saudade da familia, da cultura e das comidas (Entrevistado D); Sim, os odivelenses, que moram fora, sempre retornam por sentirem falta do cotidiano da cidade, para reviver e recordar bons momentos referentes ao rio, aos peixes, a cultura e outras coisas (Entrevistado E); Sim, os filhos da terra retornam pela família e para os momentos e datas festivas (EntrevistadoH). E são exatamente as práticas culturais e o espaço - cotidiano da família e da cidade, datas festivas, comidas - que dão o tom para a volta, como elemento que unifica em seu entorno o sentimento de ser odivelense, a odivelidade como marca identitária e sentimento de pertença do povo, em sentido inato a quem é portador dessa qualidade. Alie-se a estes depoimentos de saudosismo pelo território outras qualidades apontadas por Diegues (2002), como marca de 
comunidades tradicionais, isto é, a importância dos mitos e rituais - a reiterada brincadeira do boi de máscaras assim como os reconhecimentos de pertenças familiares - e a auto-identificação e identificação pelos Outros de pertencerem a uma cultura distinta, sendo um povo hospitaleiro e acolhedor e os bois de máscaras são uma tradição que contagia a todos (Entrevistado A). A principal referência atribuída aos odivelenses, quando estão em outros ambientes e/ou lugares, é direcionada à cidade como "terra do caranguejo" ou "terra do boi de máscaras". Ainda que haja sotaque característicos, gírias ou termos próprios na diversidade de bairros e pessoas de Odivelas, são os títulos atribuídos à cidade que marcam mais os odivelenses quando estão em outros lugares. É importante destacar que a identidade sempre é um atributo conferido pelo Outro, que não é participante da cultura odivelense, ou não é usuário contumaz das práticas culturais de determinado grupo.

Todas estas falas oriundas dos questionários podem ser organizadas, segundo a Análise do Discurso, inicialmente em duas categorias: dito e nãodito. A primeira categoria se refere ao que é "posto" literalmente pelas falas dos entrevistados, e a segunda categoria é referente ao que é "pressuposto" a partir destas falas. Estas pressuposições podem remeter, de sua ordem, a um campo semântico de afirmação ideológica quanto ao dito, que são as paráfrases, ou a um campo semântico de negação ou polêmica frente às construções frásticas do informante, que são as polissemias que abrem o confronto entre o simbólico e o político:

Compreendendo a relação da paráfrase com a polissemia [...], entre o mesmo e o diferente, o analista se propõe compreender como o político e o linguístico se inter-relacionam na constituição dos sujeitos e na produção dos sentidos, ideologicamente assinalados (ORLANDI, 2003, p. 38).

Podemos organizar o posto e o pressuposto em três colunas, em que a primeira, à esquerda, apresenta as falas recorrentes dos (as) entrevistados (as), não exatamente como falaram, mas quanto à ideia contida nas suas palavras. A coluna ao meio se reporta a quem enunciou a ideia e a terceira coluna, à direita, refere-se à interpretação dos autores deste trabalho, uma vez que o não-dito é o discurso polêmico que cria a polissemia, o que vem a ser o princípio organizador da análise, conforme disposto no Quadro 2 abaixo. 
Quadro 2-Organização das informações sistematizadas acima

\begin{tabular}{|c|c|c|}
\hline DITO & QUEM DIZ & NÃO-DITO \\
\hline $\begin{array}{l}\text { Ser odivelense é gostar dos } \\
\text { manguezais, dos cortejos de } \\
\text { bois de máscaras, das comidas } \\
\text { locais e das procissões religiosas }\end{array}$ & \multirow{6}{*}{$\begin{array}{c}\text { Professor } \\
\text { Estudante } \\
\text { Artesão } \\
\text { Aposentado } \\
\text { Pescador } \\
\text { Músico } \\
\text { Servidor Público }\end{array}$} & $\begin{array}{l}\text { Estas marcas identitárias são } \\
\text { oriundas do processo colonizador } \\
\text { brando, por isso onde estão as } \\
\text { outras matrizes étnicas do local? }\end{array}$ \\
\hline $\begin{array}{l}\text { O território odivelense é o } \\
\text { único espaço para a existência } \\
\text { dos bois de máscaras, das } \\
\text { bandas musicais e da culinária } \\
\text { do caranguejo }\end{array}$ & & $\begin{array}{l}\text { Todas estas manifestações } \\
\text { são oriundas de práticas de } \\
\text { comunidades tradicionais, qual o } \\
\text { protagonismo destas? }\end{array}$ \\
\hline $\begin{array}{l}\text { Os grupos culturais merecem } \\
\text { ser mais conhecidos fora da } \\
\text { cidade }\end{array}$ & & $\begin{array}{l}\text { Estes grupos são conhecidos no } \\
\text { município e atuam nele? }\end{array}$ \\
\hline $\begin{array}{l}\text { A cultura odivelense cria } \\
\text { características próprias ao } \\
\text { carnaval, às pescarias e ao boi- } \\
\text { bumbá }\end{array}$ & & $\begin{array}{l}\text { Quais as razões para a agregação } \\
\text { de universais em práticas locais? } \\
\text { Quem e por que o fez assim? } \\
\text { Existem interesses comerciais? }\end{array}$ \\
\hline $\begin{array}{l}\text { Os visitantes e alóctones } \\
\text { admiram as bandas e os bois, } \\
\text { a hospitalidade, o carnaval, e o } \\
\text { caranguejo }\end{array}$ & & $\begin{array}{l}\text { Para além da eventualidade, os } \\
\text { alóctones conhecem o cotidiano da } \\
\text { cidade? Quais as dificuldades em } \\
\text { manter essas características? }\end{array}$ \\
\hline $\begin{array}{l}\text { O odivelense que mora em } \\
\text { outro lugar sempre retorna } \\
\text { pelo apego à família e à rotina } \\
\text { da cidade }\end{array}$ & & $\begin{array}{l}\text { Quais as razões os moveram a sair } \\
\text { da cidade? Eles buscam preservar } \\
\text { esse patrimônio? }\end{array}$ \\
\hline
\end{tabular}

Fonte: Elaboração dos autores.

Primeiramente, é significativo dizer que a totalidade dos informantes, enquanto locutores vinculados a uma instituição social e a um viés ideológico, pertence à subalternidade, esta entendida como classe de trabalhadores não empresários ou políticos profissionais, configurando-se em uma classe social que é marca dos ativistas culturais odivelenses presentes ao Seminário. Isto implica que as manifestações são tratadas como eventos característicos do "senso de comunidade" por serem agregadores dos comuns, mesmo dos odivelenses centrífugos, visto que "a ideia de comunidade inclui um sentimento forte de pertencimento e compromisso mútuo baseado em uma cultura homogênea, experiência em comum e acentuada interdependência" (JOHNSON, 1997, p. 45). Este senso é acentuado por ser a cidade uma comunidade tradicional, que é marcada por "moradia e ocupação do território por várias gerações, ainda que 
alguns membros individuais possam ter-se deslocado para os centros urbanos e voltado para a terra de seus antepassados" (DIEGUES, 2002, p. 89).

No entanto, o pertencimento e estabelecimento ao/no espaço acaba por estereotipar o que deve ser os símbolos identitários, certamente excluindo-se as minorias pela afirmação de um todo hegemônico afirmar: somente existem os bois de máscaras em Odivelas? Somente o caranguejo é prato típico local? Por isso é necessário entender o espaço, como "um conjunto de objetos e de relações que se realizam sobre estes objetos" (SANTOS, 1997, p. 71) implicando no necessário conhecimento dos diversos segmentos da odivelidade. Por exemplo, o surgimento dos bois de máscaras está estreitamente relacionado à comunidade de pescadores, que foram os iniciadores da manifestação há mais de noventa anos. Deste vínculo com a natureza advêm as manifestações dadas como mais significantes, vinculadas aos trabalhadores do mar e do mangue, pois é quem fornece o caranguejo, quem estimula as brincadeiras no rio, quem instituiu as bandas musicais e os bois de máscaras. A inclusão e o reconhecimento de comunidades tradicionais na identidade têm a importância por ser este segmento o mais próximo das populações autóctones que estavam aqui no período précolombiano, o que começa a ser atestado por levantamentos arqueológicos que apontam uma magnífica diversidade e quantidade de sítios em Odivelas (LOPES; FERNANDES; SILVA, 2020).

O sentido de territorialidade é categoria determinante para a odivelidade, por ser o "esforço coletivo de um grupo social para ocupar, usar, controlar e se identificar com uma parcela específica de seu ambiente biofísico, convertendo-a assim em seu 'território' ou homeland" (LIT'TLE, 2003, p. 253). Para além da ocupação, uso e controle de seu território de uso, os odivelenses realizam estas operações, em seu cotidiano e em seus rituais, como formas de identificação sentimental (homeland) com seu espaço biofísico, que lhe fornece a paisagem para os cortejos dos bumbás, ao largo do rio Mojuim; a culinária que vem do mar, com caranguejos e peixes diversos; a religiosidade de agradecimento aos santos sazonais dos pescadores e a reverência ao padroeiro da cidade. E conhecer o território implica em ir mais além do evento e da circunstancialidade do turista, alcançando o vínculo com o cotidiano da cidade, que é a marca alegada pelos informantes que conduz o odivelense exilado ao retorno frequente.

Intensificando esse vínculo, deve-se lembrar que as tradições, saberes e fazeres do contexto sociocultural odivelense são transmitidas oralmente, na cumplicidade dos relacionamentos de parentesco e compadrio, em momentos performáticos tanto na exibição pública das manifestações como no aconchego das oficinas e espaços domésticos, em que o texto da sapiência ancestral se 
desenrola e se funda na memória de cada aprendente: "A transmissão de boca a ouvido opera o texto, mas é o todo da performance que constitui o locus emocional em que o texto vocalizado se torna arte e donde procede e se mantém a totalidade de energias que constituem a obra viva" (ZUMTHOR, 1993, p. 222).

\section{CONCLUSÕES}

A maioria dos odivelenses, que construíram uma vida social em outros centros ou cidades, em algum momento retorna para rever amigos, família e reviver momentos mais culturais, como brincar no boi, participar do festival do caranguejo, carnaval ou no círio do padroeiro; ou retornar para comer peixe cozido ou assado na brasa, ou comer caranguejo, ou mesmo para pescar e conviver com o ambiente proporcionado pelo rio Mojuim. Entretanto há aqueles que fazem comparações entre um lugar e outro, levando em consideração estrutura social, política e, até mesmo, cultural. Neste caso as falas são de depreciação da cidade. Do mesmo modo há aqueles que retornam com o propósito de sugerir atividades e ações, que promovam o desenvolvimento social, cultural e educacional locais, e que mantêm sua identificação com o ambiente natural, em relação com o rio, com os grupos e tradições culturais locais, com o manguezal que cerca a cidade, enfim, mantêm viva sua relação com a terra natal. Os dois casos são exemplos dos movimentos centrífugo e centrípeto, mas que consideramos como variantes de um mesmo processo, a odivelidade, também marcado pelo binarismo cultural e social, sendo essa caracterização binária de movimentos opostos e complementares o que afirma a identidade, conciliando, pelas manifestações, os que permaneceram e os que se foram.

O binarismo cultural, ademais dos movimentos centrípetos e centrífugos, tem resultado na construção de hegemonia cultural, quando os discursos convergem para o delineamento de símbolos identitários - bois de máscaras, bandas musicais, caranguejo, manguezais - na linha de uma aliança implícita entre os ativistas culturais, que mobilizam seu segmento em luta com as classes dirigentes e políticos profissionais, o que lembra a teoria gramsciana. Estes grupos, mesmo a despeito dos tensionamentos, estão em co-dependência, o que nos remete a responder ao segundo objetivo deste estudo. Portanto, a formação da identidade odivelense está pautada neste aspecto, quiçá de várias outras cidades e comunidades do interior da Amazônia, em que, como diria Veríssimo (1985), há invariavelmente o conservador e o liberal. Podemos mesmo dizer que estes agentes políticos são a metáfora que representa toda uma rede de relações sociais e culturais nestas realidades de teor mais comunal e tradicional, o que acreditamos 
ficou impingido aqui enquanto marca identitária. Esta dualidade presente em comunidades do interior da Amazônia descortina o "senso de comunidade", que é a convivência e co-dependência de "um conjunto de pessoas que compartilham de um território geográfico e de algum grau de interdependência que proporcionam a razão para viverem na mesma área" (JOHNSON, 1997, p. 45).

Em duplo sentido, os grupos sociais locais mantêm a enculturação como garantia de manutenção da tradição, sem que haja desacomodação dos papéis sociais e de poder, daí a constante afirmação pelos símbolos da odivelidade, como os já citados, que são reforçados pela transmissão intergeracional vertical, ao longo do tempo. De outro modo, os grupos centrífugos, daqueles que se foram, procedem mais à difusão, posto que no mesmo tempo e espaço tentam trazer o que seja a "novidade", pelas novas experiências adquiridas no "alémmangue", como transmissão horizontal de novos conhecimentos advindos de seus estudos alóctones. Não é demais lembrar que:

Si en toda relación social hay circulación de poder, en toda configuración el poder adquiere las peculiaridades de la hegemonía; esto es, de la producción de sentidos comunes y subalternizaciones naturalizadas. Una hegemonía no es la anulación del conflicto sino, más bien, el establecimiento de un lenguaje y un campo de posibilidades para el conflicto (GRIMSON, 2012, p. 46).

Assim, toda a arquitetura das práticas locais, das narrativas memorialistas dos indivíduos aos eventos sociais e domésticos do patrimônio cultural odivelense, estrutura-se em conformidade com grupos e manifestações co-dependentes, mesmo que aparentem uma contrariedade, o que nos autoriza a não crer que haja total isolamento das cidades locais, mesmo Odivelas. É uma lógica em que a possível belicosidade da relação se configura em uma encenação de dicotomias, que medram acordos e conflitos locais, mas que são a lógica de Jano, as duas faces da mesma moeda!

\section{REFERÊNCIAS}

ALMEIDA, I. M. X. A.; SANTOS, J. L. O. É dia de folia: o folguedo do boi de máscara em São Caetano de Odivelas/PA. Revista de Ciências Sociais, Fortaleza, v. 43, n. 2, p. 117-136, jul./dez. 2012.

BAENA, A. L. M. Ensaio corográfico sobre a província do Pará. Brasília, DF: Senado Federal, 2014.

BALÉE, W. Inside cultures. Walnut Creek, CA: Left Coast Press, 2012. 
BRASIL. Constituição da República Federativa do Brasil (1988). Brasília, DF: Senado Federal, 2006.

CANDAU, J. Memória e identidade. São Paulo: Contexto, 2016.

CARDOSO, M. R. Boi de máscaras faceiro: reflexões e contribuições metodológicas para o ensino musical infantil em São Caetano de Odivelas PA. In: JORNADA DE SABERES E VIVÊNCIAS MUSICAIS DA UEPA, 1., 2019, Bragança. Anais [...]. UEPA: Bragança, 2019. p. 1-14. Disponível em: https://www.even3.com.br/anais/jsvm_uepa/192011-boi-de-mascaras-faceiro-reflexoes-e-contribuicoes-metodologicas-para-o-ensino-musical-infantil-emsao-caetano-de/. Acesso em: 5 maio 2021.

COSME, P. B. Entre a cultura popular e a arte urbana: a cidade de São Caetano de Odivelas - Pará nos murais contemporâneos de And Santtos e Adriano DK. 2020. 194 f. Dissertação (Mestrado em Comunicação, Cultura e Amazônia) - Programa de Pós-Graduação em Comunicação, Cultura e Amazônia, Universidade Federal do Pará, Belém, 2020.

CRUZ, E. A estrada de ferro de Bragança. Belém: SPVEA, 1955.

DA MATTA, R. O que faz o brasil, Brasil? Rio de Janeiro: Rocco, 1986.

DIEGUES, A. C. O mito moderno da natureza intocada. 4. ed. São Paulo: Hucitec: Annablume, 2002.

FERNANDES, J. G. S. O boi de máscaras: festa, trabalho e memória na cultura popular do Boi Tinga de São Caetano de Odivelas, Pará. 2004. 180 f. Tese (Doutorado em Letras) - Programa de Pós-Graduação em Letras, Universidade Federal da Paraíba, João Pessoa, 2004.

FERNANDES, J. G. S. O boi de máscaras: festa, trabalho e memória na cultura popular do Boi Tinga de São Caetano de Odivelas, Pa. Belém: EDUFPA, 2007.

FERNANDES, J. G. S. Pés que andam, pés que dançam: memória, identidade e região cultural na esmolação e marujada de São Benedito em Bragança (Pa). Belém: EDUEPA, 2011.

GRAMSCI, A. Quelques thèmes de la question méridionale (1926). Marxists Internet Arcive, [s. l.], 2021. Disponível em: https://marxists. architexturez.net/francais/gramsci/works/1926/10/gramsci_19261000.pdf. Acesso em: 5 maio 2021. 
GRIMSON, A. Los límites de la cultura. Buenos Aires: Siglo XXI, 2012. HALL, S. A identidade cultural na pós-modernidade. Rio de Janeiro: DP \& A, 2000.

IBGE. Estimativas da população residente no Brasil e unidades da federação com data de referência em $1^{\circ}$ de julho de 2019. IBGE, Rio de Janeiro, 2019. Disponível em: https://agenciadenoticias.ibge.gov.br/media/com_mediaibge/ arquivos/7d410669a4ae85faf4e8c3a0a0c649c7.pdf. Acesso em: 25 maio 2021.

JOHNSON, A. G. Dicionário de sociologia. Rio de Janeiro: Jorge Zahar Editor, 1997.

LITTLE, P. E. Territórios sociais e povos tradicionais no Brasil: por uma antropologia da territorialidade. Anuário Antropológico, Brasília, DF, v. 1, n. 322, p. 251-290, 2003. Disponível em: https://periodicos.unb.br/index.php/ anuarioantropologico/article/view/6871/7327. Acesso em: 8 maio 2020.

LOPES, P. R. C.; FERNANDES, J. G. S.; SILVA, F. M. Povo do mangue: antropização e vestígios arqueológicos na Península Odivelense. Espaço Ameríndio, Porto Alegre, v. 14, n. 1, p. 265-289, jan./jul. 2020.

LOUREIRO, J. J. P. Cultura amazônica: uma poética do imaginário. Belém: Cejup, 1995.

ROMÃO, Filipe Luís de Vasconcelos. Nacionalismos centrípetos e centrífugos e conflitualidade: o caso espanhol. 2012. 314 f. Tese (Doutorado em Relações Internacionais) - Faculdade de Economia, Universidade de Coimbra, Coimbra, 2012.

SANTOS, M. Metamorfose do espaço habitado. 5. ed. São Paulo: Hucitec, 1997.

SANTOS, M. Da totalidade ao lugar. São Paulo: EDUSP, 2008.

SILVA, S. S. S. Boi Tinga: um cortejo de caricaturas em São Caetano de Odivelas. 2004. 168 f. Dissertação (Mestrado em Artes Cênicas)

- Programa de Pós-Graduação em Artes Cênicas, Universidade Federal da Bahia, Salvador, 2004.

SILVA, S. S. S. Tradição e contemporaneidade: o corpo e os processos de aprendizagem na dança do boi de São Caetano de Odivelas. Ensaio Geral, Belém, v. 1, n. 2, p. 170-178, jul./dez. 2009. 
SILVA, S. S. S. O boi e a máscara: imaginário, contemporaneidade e espetacularidade nas brincadeiras de boi de São Caetano de Odivelas - Pará. 2011. 244 f. Tese (Doutorado em Artes Cênicas) - Programa de Pós-Graduação em Artes Cênicas, Universidade Federal da Bahia, Salvador, 2011.

VELHO, O. G. Frentes de expansão e estrutura agrária. Rio de Janeiro: Zahar Editores, 1981.

VERÍSSIMO, J. A educação nacional. Porto Alegre: Mercado Aberto, 1985.

WILLIAMS, R. Palavras-chave: um vocabulário de cultura e sociedade. São Paulo: Boitempo, 2007.

WILLIAMS, R. Cultura. São Paulo: Paz e Terra, 2000.

ZUMTHOR, P. A letra e a voz. São Paulo: Companhia das Letras, 1993. 